\title{
A PSIQUE E A ACUPUNTURA ${ }^{1}$
}

\author{
The Psique and the Acupuntura
}

André Luiz Picolli da Silva²

Campiglia, Helena (2004). Psique e medicina tradicional chinesa. São Paulo: Rocca.

A unificação dos conhecimentos do oriente e do ocidente é, cada vez mais, uma realidade inevitável. A evolução a que chegou o conhecimento humano possibilita, hoje, nesse início do século XXI, unificar conhecimentos que no passado foram considerados antagônicos, como a Ciência e a Tradição. Um exemplo dessa unidade é o que se encontra na obra "Psique e Medicina Tradicional Chinesa", de Helena Campiglia, na qual a autora, com grande propriedade, estabelece e fundamenta relações claras e precisas entre a produção mais atual da Ciência Psicológica ocidental e a produção milenar da Medicina Tradicional Chinesa, em especial a Acupuntura. Essas relações, aliadas à habilidade em escrever com uma linguagem acessível ao mesmo tempo ao coloquial e ao acadêmico, fazem com que a leitura seja "como o Oriente", misteriosa e instigante, e "como o Ocidente", prática e objetiva.

Segundo a autora, que é médica acupunturista, a idéia de produzir um livro que relacionasse princípios aparentemente tão distantes surgiu após realização de uma monografia intitulada "Reich e a Medicina Tradicional Chinesa", por intermédio da qual pôde perceber que a teoria reichiana apresentava um grande paralelismo com a tradição da Medicina Chinesa. Além disso, a autora também se dedicou ao estudo da teoria junguiana para sua formação profissional e, assim, da união desses três conhecimentos, "surgiu" o livro que é dividido em duas partes. A primeira, denominada "A Psique na Medicina Chinesa”, apresenta capítulos que relacionam temas como: o yin yang e os símbolos; Qi, energia vital, libido e energia psíquica; os cinco elementos na Medicina Tradicional Chinesa. Na segunda parte do livro, denominada "Distúrbios psíquicos na Medicina Chinesa", são apresentados capítulos que tratam de temas como: fatores de adoecimento; psicopatologia na Medicina Chinesa; pontos de acupuntura no tratamento de distúrbios psíquicos; terapias de abordagem corporal e simbólica.

Resenha do livro: Psique e medicina tradicional chinesa. De Helena Campiglia, publicado em 2004, em São Paulo, pela editora Roca, com 226 páginas.

2 Coordenador do Curso de Graduação em Psicologia da Faculdade Seama, Mestre em Psicologia pela Universidade Federal de Santa Catarina (UFSC).e-mail: anpicolli@yahoo.com.br 
Ao longo de toda obra e em especial nos primeiros capítulos, é enfatizado que a Medicina Tradicional Chinesa, assim como as teorias Junguiana e Reichiana, apresentam grandes semelhanças, pois todas entendem o ser humano como uma unidade entre psique e soma, quer pelos aspectos energéticos, pela caracterologia ou pela dimensão do símbolo. É nesta perspectiva que a autora relaciona a influência do I-Ching, livro tradicional chinês sobre a compreensão da saúde/doença na Medicina Chinesa. O modo chinês de compreender esse fenômeno enfatiza que a saúde no homem está em constante mutação e em busca de um equilíbrio. Essa concepção milenar curiosamente também é mais aceita atualmente no "universo das psicoterapias ocidentais", graças a uma compreensão semelhante advinda das mudanças ocorridas na física e matemática no início do século XX.

Por intermédio dessa "ampliação de compreensão", os cientistas do ocidente começaram a entender melhor alguns conceitos que há milênios são utilizados pelos chineses, como a noção de Yin e Yang $^{3}$, graças a um maior entendimento das dimensões simbólicas desses conceitos. A compreensão simbólica é um "ponto-chave" tratado no livro. Em uma perspectiva junguiana, o símbolo não pode ser visto como algo estanque, inanimado, pois nos relacionamos ativamente com ele com relações de dor, prazer e alegria. Os símbolos são imagens carregadas de uma energia emocional (individual ou coletiva). O símbolo abarca a totalidade do que representa, mesmo sendo só uma parte do todo.

Pensar simbolicamente é difícil ao ocidental acostumado à lógica cartesiana, pois o "universo simbólico" não é linear como a lógica, mas, sim, circular. No oriente "se pensa" por imagens e não por conceitos, assim, a própria linguagem (nos ideogramas, por exemplo), chinesa, japonesa, egípcia favorece a captação de um símbolo nos seus mais diversos significados. Muitos símbolos mantidos no oriente são antiqüíssimos, e um exemplo desses símbolos é o ideograma da palavra "Qi", que no ocidente foi traduzida como "energia", mas que literalmente significa "respiração sobre o arroz não cozido". O que o ideograma (ou o símbolo) "tenta passar" é a idéia de potencialidade para se transformar em alimento, para fazer as coisas. Assim, o "vapor quente", "transforma" o "arroz cru" em "arroz cozido", daí a possível tradução de "Qi" como "energia".

Assim como a Linguagem chinesa, a Medicina também é simbólica. As doenças eram explicas há 3 mil anos de forma simbólica: "a invasão do vento", "ataque do frio perverso", "fogo consumindo o coração". O funcionamento do organismo (soma e psique) também foi explicado de modo simbólico por intermédio da relação entre dois princípios, Yin e Yang, e de cinco elementos (terra, metal, água, madeira e fogo). No livro, é feita uma excelente demonstração sobre as relações de "criação" e de "dominância" existentes entre esses cinco elementos ou movimentos, na qual é enfatizado que esse "sistema de relações" proporciona o equilíbrio em todas as coisas, inclusive no ser humano, no qual o desequilíbrio é caracterizado como patologia.

No livro também é realizada uma excelente explanação sobre o conceito de energia, sendo relacionados mais especificamente os conceitos de "Qi" ou "energia vital" no oriente e de "libido" ou "energia psíquica" no ocidente. Para os chineses, o "Qi" não está só no homem, mas em todo o universo, isso coloca o homem diretamente interligado em um sistema de relações com o universo. Fica claro, assim, que é impossível, na concepção da Medicina Tradicional Chinesa, separar psíquico do orgânico e esses da natureza, pois todos eles são aspectos diferentes de uma mesma energia.

Com grande propriedade, a autora apresenta no livro que a idéia de energia não é algo novo também no ocidente. Freud já descreveu a existência de uma "certa energia" que impulsiona o homem ao movimento a qual denominou de "Libido". Reich, que expandiu a idéia da "Libido" para o "Orgônio", também havia percebido que a "energia em movimento" proporcionava a saúde e o seu bloqueio levava ao surgimento das neuroses. Do mesmo modo, Jung também estudou a energia, ampliando o conceito de Libido para além da sexualidade, utilizando o conceito de "Energia Psíquica". Nessa perspectiva, é interessante o enfoque realizado no livro, no qual é demonstrado que o conceito de "Qi" da Medicina Tradicional

\footnotetext{
A base da medicina tradicional chinesa, duas "formas" de uma mesma energia que são ao mesmo tempo antagônicas e complementares.
} 
Chinesa engloba os conceitos de Libido, Orgônio e Energia Psíquica de Freud, Reich e Jung, pois apresenta características pessoais e universais que vão do biológico sexual ao existencial espiritual.

Sempre traçando paralelos com teorias psicológicas do ocidente, a fim de compreender o psiquismo tanto na concepção ocidental quanto oriental, é apresentada uma relação entre a caracterologia reichiana e a teoria dos cinco elementos da Medicina Chinesa. Assim, no livro, são apresentadas possíveis relações entre o elemento água e tipo fóbico, a madeira e o tipo fálico narcisista, o fogo e o tipo histérico, a terra e o tipo oral, o metal e o tipo anal. Ampliando essas relações, também são explanados os aspectos mentais e espirituais na Medicina Chinesa, conhecidos como "Shen", "Po", "Hun", "Yi" e "Zhi".

Na segunda parte do livro, a autora se detém especificamente à parte de distúrbios psíquicos na Medicina Tradicional Chinesa. Nesta, é entendido que tanto o orgânico e o psíquico adoecem juntos, não sendo possível uma visão de causalidade, mas, sim, de múltiplas relações de variáveis. Assim, para a Medicina Tradicional Chinesa, a doença é uma decorrência do desequilíbrio do organismo, que pode ocorrer por fatores internos (emoções, diminuição da energia vital, hereditariedade), fatores externos (clima, meio ambiente, vírus), chamados de "energias perversas", ou fatores nem internos nem externos, como excessos de relações sexuais, de trabalho, de exercícios físicos, alimentação, traumas, etc.

$\mathrm{Na}$ Medicina Tradicional Chinesa, os textos clássicos mostram que as doenças mentais estão relacionadas a dois órgãos: ao coração, que "guarda o espírito", e ao fígado, que "rege as emoções". Porém, cada elemento dos cinco elementos está envolvido na "construção da psique" e qualquer alteração nos elementos pode originar uma psicopatologia diferente. Assim, a autora descreve sobre as psicopatologias da água, madeira, fogo, terra e metal, suas características e formas de intervenção, apresentando um capítulo inteiro só sobre pontos e acupuntura, que podem ser utilizados para tratamentos de distúrbios psíquicos.

Aliado às combinações dos pontos de acupuntura apresentados para a realização de intervenções desses distúrbios, no livro também são apresentadas outras formas e combinações de tratamentos, como utilização da fitoterapia, dietas e exercícios meditativos. Na parte final do livro, a autora faz relação entre partes específicas do corpo, como olhos, peito, diafragma, pelves, e as diferentes formas de compreensão e trabalhos dessas partes do corpo na psicoterapia corporal ocidental e na Medicina Tradicional Chinesa.

Desse modo, o livro de Helena Campiglia consiste em uma obra que proporciona uma leitura rica e ao mesmo tempo agradável, sendo indicada para todos os que tenham interesse pelo assunto e praticamente indispensável para os profissionais e estudantes das áreas Humanas e da Saúde, que se dedicam à utilização de técnicas ocidentais e orientais. É uma obra envolvente e sedutora, criativa e objetiva, inquietante e reveladora, como o próprio tema a que se pretende estudar.

Recebido em: 10/04/2007

Received in: 04/10/2007

Aprovado em: 02/05/2007

Approved in: 05/02/2007 